\title{
Evaluation of expression of VDR-associated IncRNAs in COVID-19 patients
}

Mohammad Taheri', Lina Moallemi Rad ${ }^{2}$, Bashdar Mahmud Hussen ${ }^{3}$, Fwad Nicknafs ${ }^{4}$, Arezou Sayad ${ }^{4 *}$ and Soudeh Ghafouri-Fard ${ }^{4 *}$

\begin{abstract}
Background: Coronavirus disease 2019 (COVID-19) has been shown to cause serious health problems among them is the Acute Respiratory Distress syndrome (ARDS). Vitamin D receptor (VDR) signaling possibly partakes in the pathophysiology of this devastating complication.

Methods: In the current project, we have appraised expression levels of VDR, CYP27B1 and a number of associated IncRNAs in the circulation of COVID-19 patients versus healthy subjects using real-time PCR method.

Results: Expression of SNHG6 was considerably lower in COVID-19 patients compared with control subjects (Ratio of mean expression $(\mathrm{RME})=0.22, P$ value $=7.04 \mathrm{E}-05)$ and in both female and male COVID-19 patients compared with sex-matched unaffected individuals ( $R M E=0.32, P$ value $=0.04$ and $R M E=0.16$, $P$ value $=0.000679683$, respectively). However, its expression was similar among ICU-hospitalized and non-ICU patients. Similarly, expression of SNHG16 was lower in in COVID-19 patients compared with controls (RME $=0.20, P$ value $=5.94 \mathrm{E}-05$ ) and in both female and male patients compared with sex-matched controls ( $R M E=0.32, P$ value $=0.04$ and $R M E=0.14, P$ value $=0.000496435$, respectively) with no significant difference among ICU-hospitalized and non-ICU hospitalized patients. Expression of VDR was lower in COVID-19 patients compared with controls (RME $=0.42, P$ value $=0.04$ ) and in male patients compared with male controls $(R M E=0.27, P$ value $=0.02)$. Yet, expression of VDR was statistically similar between female subgroups and between ICU-hospitalized and non-ICU hospitalized patients. Expression levels CYP27B, Linc00511 and Linc00346 were similar among COVID-19 patients and healthy subjects or between their subgroups. Significant correlations have been detected between expression levels of VDR, CYP27B and SNHG6, SNHG16, Linc00511 and Linc00346 IncRNAs both among COVID-19 patients and among healthy controls with the most significant ones being SNHG6 and SNHG16 ( $r=0.74$, $P$ value $=3.26 \mathrm{e}-17$ and $r=0.81, P=1.54 \mathrm{e}-22$, respectively).

Conclusion: Combination of transcript levels of VDR, CYP27B and SNHG6, SNHG16, Linc00511 and Linc00346 could differentiate patients from controls with $A \cup C=0.76$, sensitivity $=0.62$ and specificity $=0.81$. The current data potentiate SNHG6, SNHG16 and VDR as possible contributors in COVID-19 infection but not in the severity of ARDS.
\end{abstract}

Keywords: COVID-19, Vitamin D receptor, VDR, IncRNA, SNHG6, SNHG16, Linc00511, Linc00346, CYP27B

\footnotetext{
*Correspondence: ar.sayad@yahoo.com; s.ghafourifard@sbmu.ac.ir

${ }^{4}$ Department of Medical Genetics, Shahid Beheshti University of Medical Sciences, Tehran, Iran

Full list of author information is available at the end of the article
}

(C) The Author(s). 2021 Open Access This article is licensed under a Creative Commons Attribution 4.0 International License, which permits use, sharing, adaptation, distribution and reproduction in any medium or format, as long as you give appropriate credit to the original author(s) and the source, provide a link to the Creative Commons licence, and indicate if changes were made. The images or other third party material in this article are included in the article's Creative Commons licence, unless indicated otherwise in a credit line to the material. If material is not included in the article's Creative Commons licence and your intended use is not permitted by statutory regulation or exceeds the permitted use, you will need to obtain permission directly from the copyright holder. To view a copy of this licence, visit http://creativecommons.org/licenses/by/4.0/ The Creative Commons Public Domain Dedication waiver (http://creativecommons.org/publicdomain/zero/1.0/) applies to the data made available in this article, unless otherwise stated in a credit line to the data. 


\section{Background}

Coronavirus disease 2019 (COVID-19) has been shown to cause serious health problems. The most devastating complication of this disorder is the Acute Respiratory Distress syndrome (ARDS) [1] which is thought to be caused by a mixture of mechanisms among them are cytokine storm [2], abnormal activity of the reninangiotensin apparatus [3], neutrophil stimulation [4] and enhanced coagulation [5]. This COVID-19 complication has been shown to be provoked by vitamin $\mathrm{D}$ deficiency and attenuated by induction of the vitamin $\mathrm{D}$ receptor (VDR) [6]. This observation is supported by the presence of VDR on immune cells, the regulatory role of the active vitamin $\mathrm{D}$ hormone on expression of the majority of cytokines and the role of this hormone on activation of immune defense responses while attenuation of the acquired immune responses [7-9]. Antimicrobial function of vitamin D is exerted through a cascade of events. Macrophages respond to microbial infection through pattern recognition receptors. Induction of these responses leads to activation of transcription of $1 \alpha$ hydroxylase (CYP27B1) and VDR [10]. The impact of vitamin $\mathrm{D}$ on regulation of immune responses is modulated by availability of 25-hydroxyvitamin $\mathrm{D}$, activation of CYP27B1 by the attacking pathogenic organisms and induction of 1,25-dihydroxyvitamin D in cellular compartments of the immune system $[10,11]$. Moreover, expression of VDR has been shown to be affected by several mechanisms among them are long non-coding RNAs (lncRNAs) [12]. We have previously assessed expression of VDR-associated lncRNAs namely SNHG16, SNHG6, LINC00346 and LINC00511 in a number of disorders including epilepsy [13], lung cancer [14] and breast cancer [15]. In the current project, we have appraised expression levels of VDR, CYP27B1 and mentioned lncRNAs in the circulation of COVID-19 patients versus healthy subjects to unravel the role of these transcripts in the pathogenic processes during the course of COVID-19.

\section{Methods}

\section{Enrolled individuals}

This study is a pilot study to measure expression levels of $V D R$ and related lncRNAs in COVID-19 cases and healthy controls. The current investigation was conducted on patients hospitalized to Nikan Hospital, Tehran, during March 2020 until April 2020. Patients have clinical manifestations of COVID-19 and the disorder was confirmed by a positive nasopharyngeal swab specimen. Patients were diagnosed to have moderate, severe and very severe disease courses and were assigned hospital treatment [16]. Control specimens were got from healthy persons without no clinical signs or recent exposure to patients with COVID-19. The study protocol was approved by ethical committee of Shahid Beheshti University of Medical Sciences. Informed consent was obtained from all patients. Paraclinical data was obtained from all hospitalized patients. Hematological tests were performed in Beckman Coulter MAXM AL Hematology Flow Cytometry System. C-reactive protein (CRP) was measured by latex-enhanced nephelometry.

\section{Expression assays}

First, $4 \mathrm{ml}$ of peripheral blood were collected from all hospitalized patients and healthy persons. Subsequently, total RNA was isolated from these specimens using the GeneAll Kit (Seoul, South Korea). Then, total RNA was transformed to cDNA using the OneStep RT-PCR Series Kit (BioFact ${ }^{\mathrm{Tm}}$, Seoul, South Korea). Transcript quantities of VDR-associated genes were measured in specimens gathered from COVID-19 patients and healthy subjects using the RealQ Plus 2x Master Mix (Amplicon, Denmark). Primers Characteristics have been reported in our previous studies $[13,15]$.

\section{Data analysis}

$\mathrm{R}$ programming language was used for data analysis. Transcript quantities of VDR-associated genes were quantified from $\mathrm{Ct}$ values, considering $B 2 M$ as the reference gene. The obtained values were $\log 2$ transformed and used for next steps. Expression levels of genes were compared between COVID-19 patients and healthy subjects and ICU-hospitalized and non-ICU hospitalized patients. The significance of difference in mean values of gene expression between two subgroups was computed using the t-test. Correlations between expression levels of genes were appraised via calculation of Spearman correlation coefficients. ROC curves were depicted using Bayesian Generalized Linear Model, Generalized Linear Model (GLM), and Linear Discriminant Analysis with 10 -fold cross validation. Application of the GLM resulted in the most appropriate estimates. Youden's J parameter was measured to find the optimum threshold. $P$ value $<0.05$ was considered as significant.

\section{Results}

Totally, 91 COVID-19 patients (38 females, 53 males) and 91 healthy subjects (39 females, 52 males) were included in the study. The mean age ( \pm standard deviation) of the COVID-19 patients was $57.18( \pm 16.89)$ years. Thirty seven patients $(40.6 \%)$ were hospitalized in the ICU. Table 1 displays the paraclinical variables obtained from medical records of the COVID-19 patients.

\section{Expression assays}

Figures 1 and 2 depict relative expressions of $V D R$, CYP27B and SNHG6, SNHG16, Linc00511 and Linc00346 lncRNAs in total COVID-19 patients 
Table 1 Paraclinical data of the COVID-19 patients

\begin{tabular}{lll}
\hline Variable & Mean & Standard deviation \\
\hline White Blood Cells $\left(10^{9} / \mathrm{L}\right)$ & 8.119 & 8.482 \\
Red Blood Cells $\left(10^{12} / \mathrm{L}\right)$ & 4.681 & 0.768 \\
Hemoglobin $(\mathrm{g} / \mathrm{dL})$ & 12.704 & 2.182 \\
Hematocrit $(\%)$ & 39.267 & 6.595 \\
MCV (fl) & 83.985 & 5.702 \\
MCH (pg) & 27.154 & 2.330 \\
MCHC (g/dL) & 32.348 & 1.3720 \\
Platelet count (10 $/ \mathrm{L})$ & 210.354 & 95.216 \\
Lymphocyte $(\%)$ & 21.043 & 11.323 \\
Neutrophil (\%) & 69.098 & 13.087 \\
ESR (mm/hr) & 44.131 & 32.701 \\
CRP (mg/dL) & 73.256 & 69.540 \\
\hline
\end{tabular}

compared with healthy persons, and in ICU-hospitalized patients compared with non-ICU patients, respectively.

Expression of SNHG6 was remarkably lower in COVID-19 patients compared with controls (Ratio of mean expression $(\mathrm{RME})=0.22, P$ value $=7.04 \mathrm{E}-05)$ and in both female and male affected individuals compared with sex-matched controls $(\mathrm{RME}=0.32, \mathrm{P}$ value $=0.04$ and $\mathrm{RME}=0.16, P$ value $=0.000679683$, respectively) .
However, its expression was statistically similar between ICU-hospitalized and non-ICU hospitalized patients. Similarly, expression of SNHG16 was lower in in COVID-19 patients compared with controls $(\mathrm{RME}=$ $0.20, P$ value $=5.94 \mathrm{E}-05)$ and in both female and male affected individuals compared with sex-matched healthy subjects $(\mathrm{RME}=0.32, P$ value $=0.04$ and $\mathrm{RME}=0.14, \mathrm{P}$ value $=0.000496435$, respectively) with no significant difference among ICU-hospitalized and non-ICU hospitalized patients. Expression of VDR was lower in COVID19 patients compared with controls $(\mathrm{RME}=0.42, P$ value $=0.04)$ and in male patients compared with normal males $(\mathrm{RME}=0.27, \mathrm{P}$ value $=0.02)$. However, expression of VDR was statistically similar between female patients and normal females and between ICU-hospitalized and non-ICU hospitalized patients. Expression levels CYP27B, Linc00511 and Linc00346 were not different between COVID-19 patients and healthy subjects or between their subgroups (Table 2).

Significant correlations have been displayed between expression levels of VDR, CYP27B and SNHG6, SNHG16, Linc00511 and Linc00346 IncRNAs both among COVID-19 patients and among healthy controls with the most significant ones being SNHG6 and SNHG16 $(\mathrm{r}=0.74, P$ value $=3.26 \mathrm{e}-17$ and $\mathrm{r}=0.81, P=$ 1.54e-22, respectively) (Figs. 3 and 4 ).

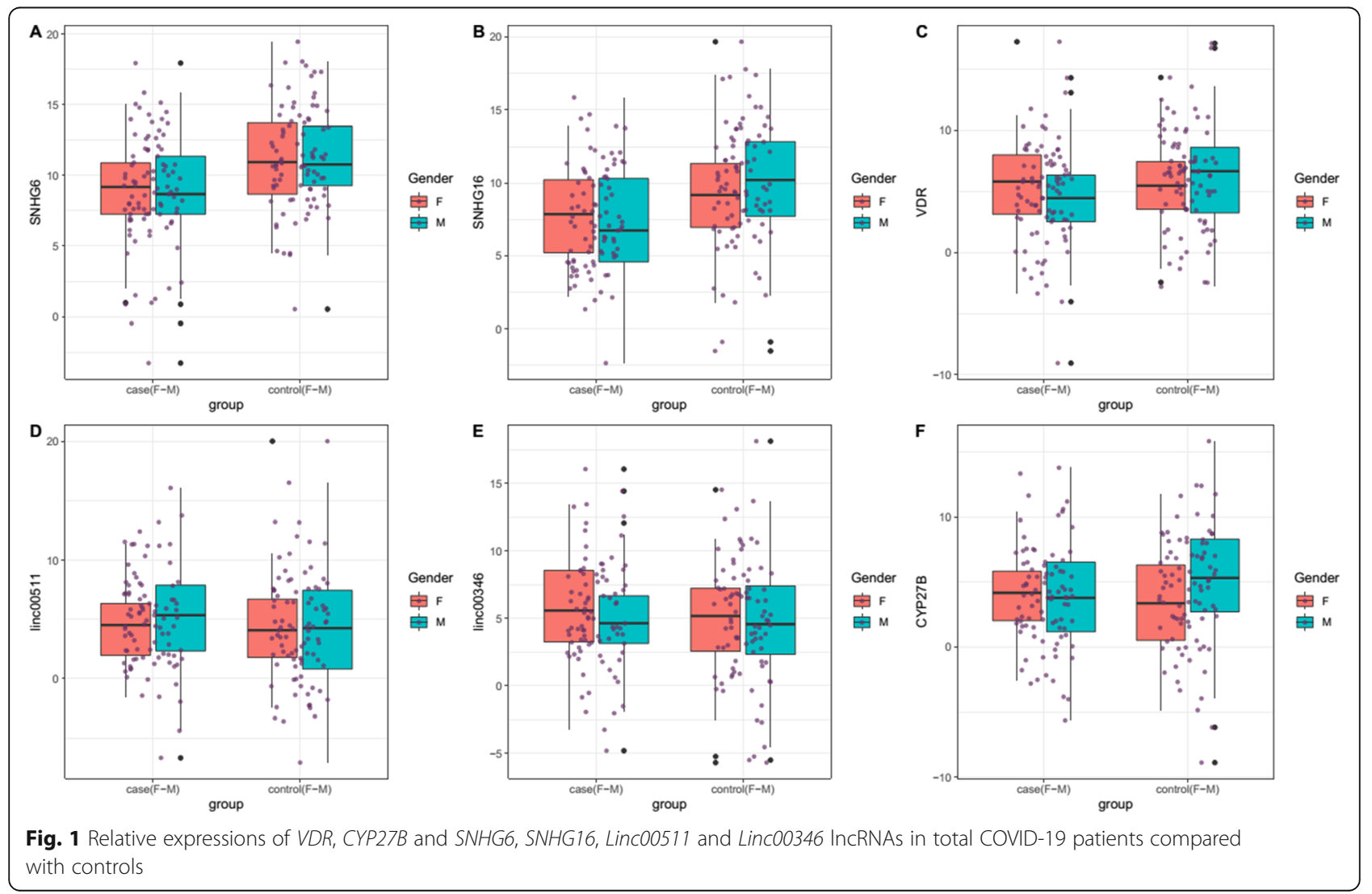




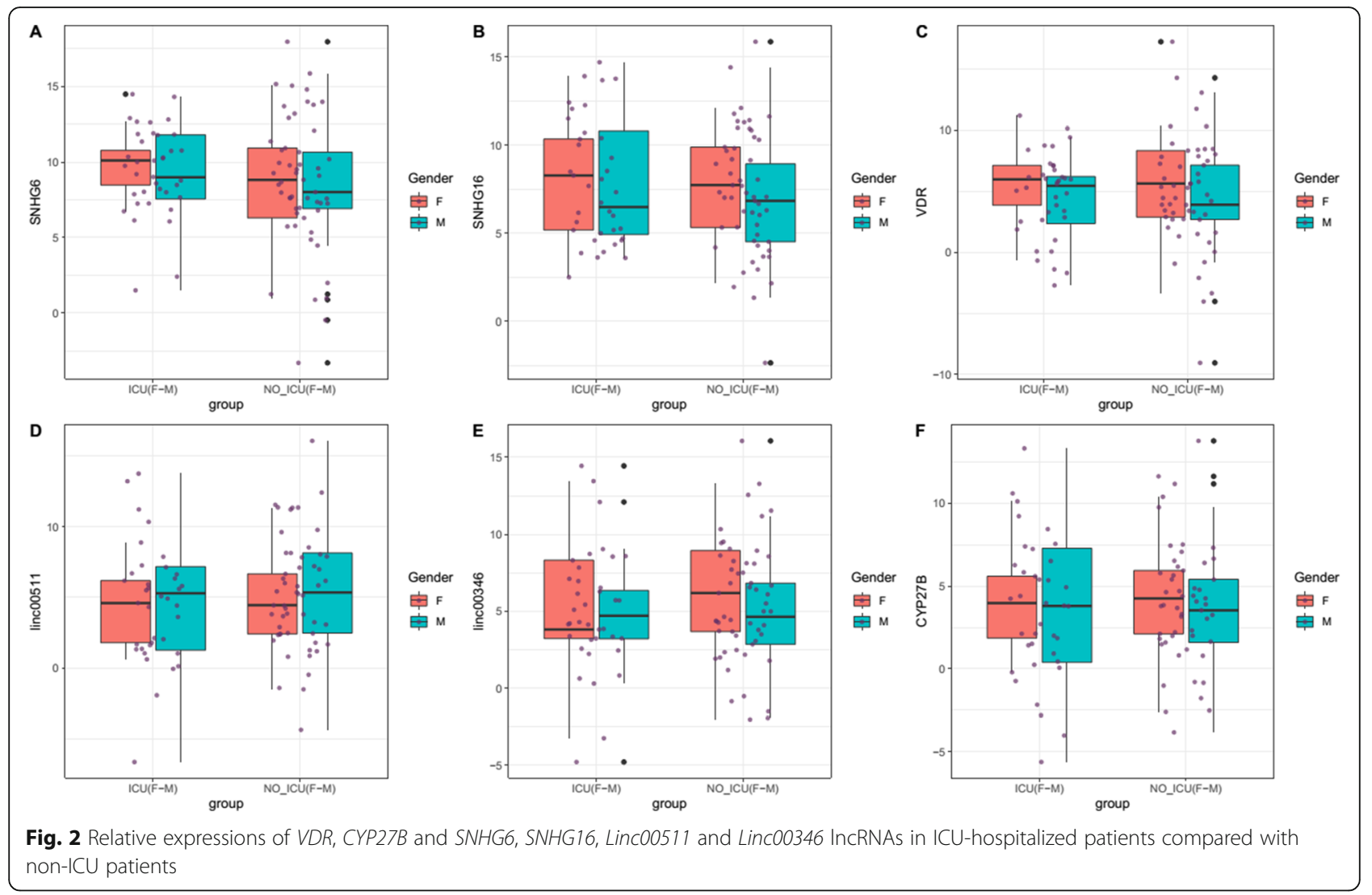

Next, we appraised correlation between expression levels of mentioned genes and patients' gender and age as well as some paraclinical parameters demonstrating no robust correlations (Fig. 5).

Finally, the diagnostic power of $V D R, C Y P 27 B$ and SNHG6, SNHG16, Linc00511 and Linc00346 has been appraised in distinguishing COVID-19 patients from healthy controls and in distinguishing ICU-hospitalized patients from the other group of patients (Fig. 6).

While none of the individual genes could appropriately distinguish COVID-19 patients from healthy controls or ICU-hospitalized patients from non-ICU-hospitalized one, combination of transcript levels of $V D R, C Y P 27 B$ and SNHG6, SNHG16, Linc00511 and Linc00346 could differentiate patients from controls with $\mathrm{AUC}=0.76$, sensitivity $=0.62$ and specificity $=0.81$. However, this type of analysis revealed no suitable diagnostic power for distinguishing ICU-hospitalized patients from non-ICUhospitalized one (Table 3).

\section{Discussion}

Vitamin D deficiency and defects in activation of VDR have been found to intensify respiratory syndrome in COVID-19 through inducing a wounding response in stellate cells of the respiratory system [17]. Moreover, vitamin $\mathrm{D}$ levels have been found to be associated with the number of COVID-19 cases/million as well as number of deaths from COVID-19/ million [18]. Based on the presence of extensive evidence regarding the role of VDR signaling in the pathogenic course of COVID-19 and its devastating complication i.e. ARDS, we have appraised expression levels of $V D R, C Y P 27 B 1$ and some VDR-associated IncRNAs in the peripheral blood of COVID-19 patients versus healthy subjects. We reported lower expressions of SNHG6 and SNHG16 in COVID-19 patients of both sexes compared with sex-matched controls. In addition, expression of $V D R$ was lower in COVID-19 patients compared with controls and in male patients compared with male controls. Conversely, expression of $V D R$ was statistically similar between female patients and normal females. Expression of none of genes was different between ICU-hospitalized and nonICU hospitalized patients. SNHG6 has been shown to activate TGF- $\beta /$ Smad signaling pathway [19]. The interaction between coronaviruses and this pathway is complicated. For instance, SARS-associated coronavirus (SARS-CoV) nucleocapsid protein has been shown to enhance TGF- $\beta$-associated expression of PAI- 1 but decreasing Smad3/Smad4-asociated apoptosis of lung epithelial cells [20]. On the other hand, SARS-CoV-2 infection has been shown to increase TGF- $\beta$ production [21]. Moreover, in severe COVID-19, SARS-CoV-2 has 


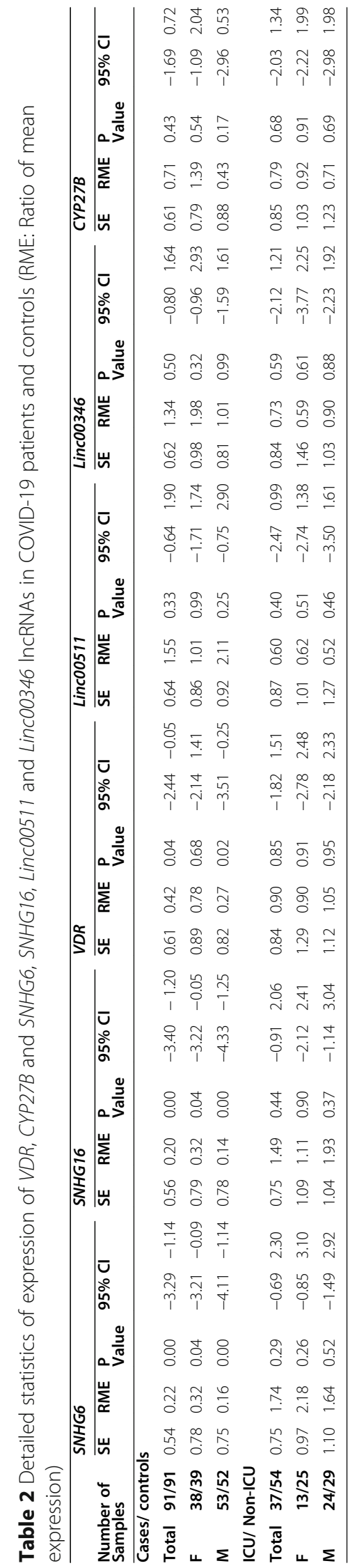




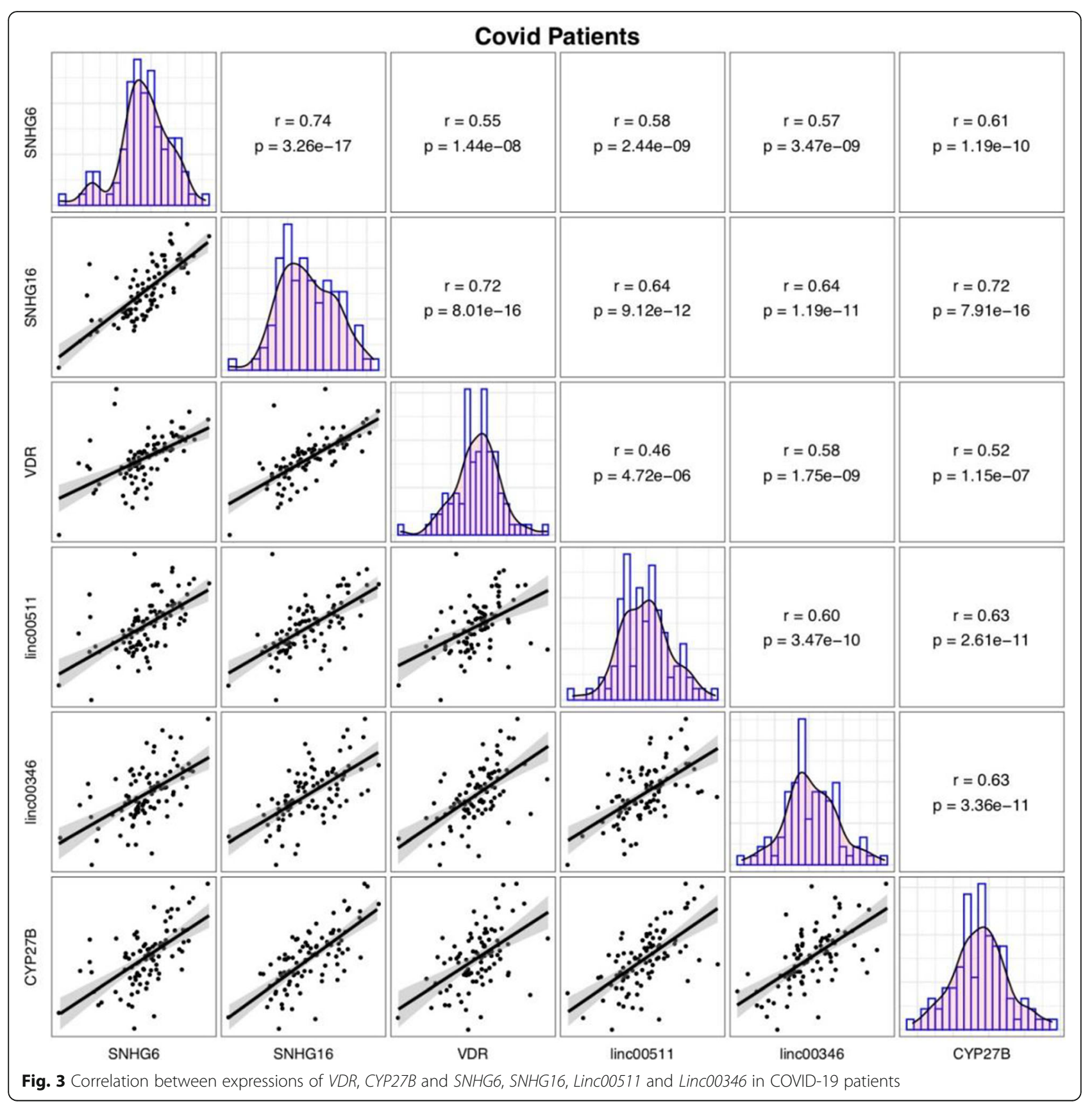

been found to induce TGF- $\beta$-dominated chronic immune responses that do not target SARS-CoV-2 antigens [22]. Several viruses alter TGF- $\beta$ signaling to inhibit cell apoptosis and enhance proliferation of fibroblasts and differentiation of myofibroblasts [23]. Over-production of TGF- $\beta$ has been reported in acute-phase SARS and COVID-19 in relation with the development of lung fibrosis. Moreover, this phenomenon has been detected in autopsy samples and a considerable percentage of SARS, MERS and COVID-19 survivors [17]. Therefore, upregulation of TGF- $\beta$ in COVID-19 patients might contribute in the lung fibrosis [21]. The observed down- regulation of SNHG6 in the peripheral blood of COVID19 patients might be due to a regulatory feedback loop between this IncRNA and TGF- $\beta$.

SNHG16 has been shown to activate TGF- $\beta 1 /$ SMAD5 pathway via miR-16-5p/SMAD5-regulatory cascade, therefore activating CD73 expression in $\gamma \delta 1 \mathrm{~T}$ cells [24]. Down-regulation of SNHG16 in COVID-19 patients might result in decreased proportion of $\gamma \delta 1 \mathrm{~T}$ cells, thus activation of pro-inflammatory cascades and pulmonary fibrosis, since some subsets of $\gamma \delta \mathrm{T}$ cells regulate immunosuppressive functions and induce immune tolerance in certain contexts [25]. 


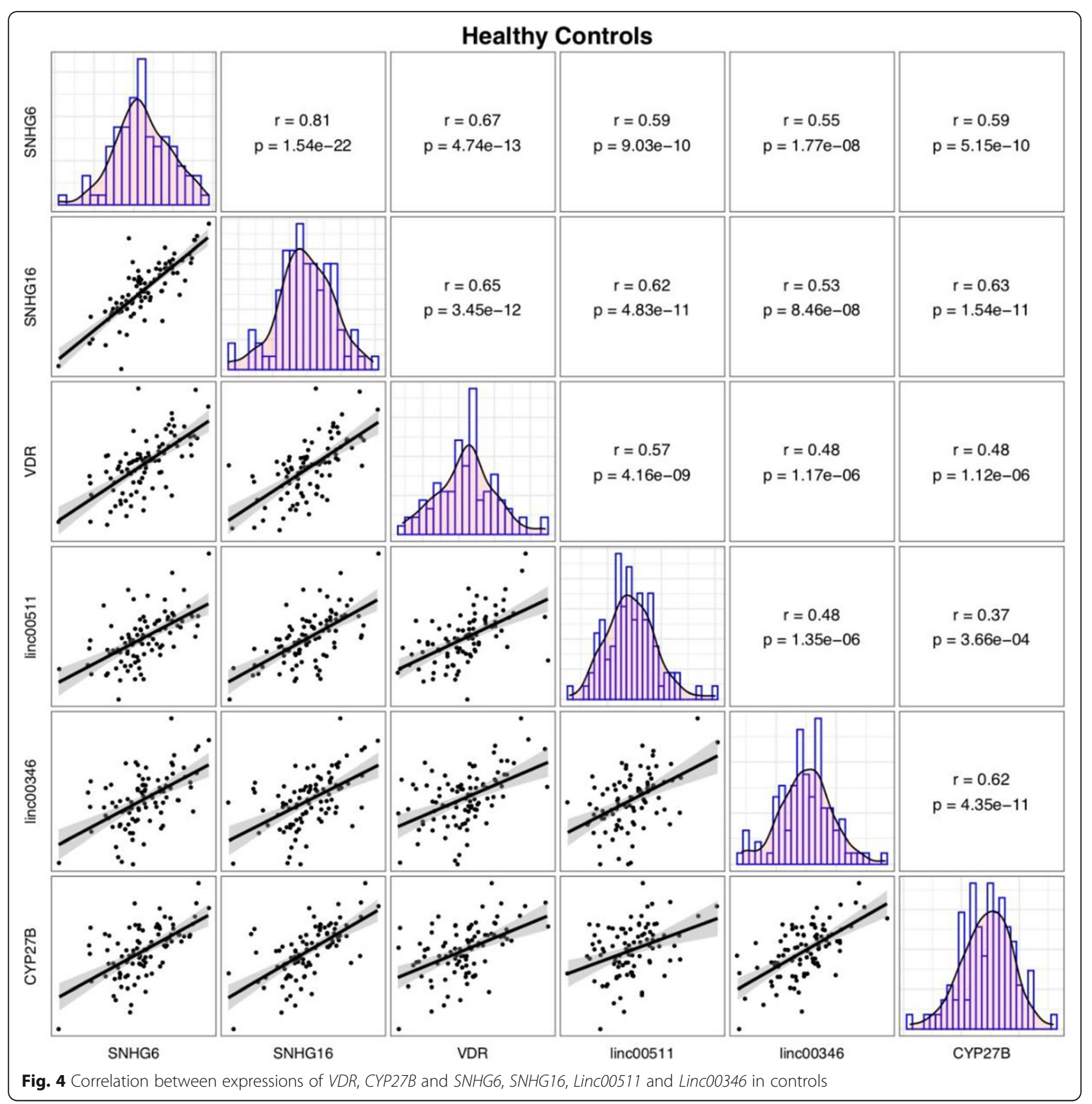

It is not clear whether the observed decreased level of $V D R$ in COVID-19 is the cause or effects of COVID-19. However, previous studies have indicated that certain polymorphisms in the VDR gene might have adverse impact on the outcome of patients with COVID-19 [26, 27]. Therefore, we suggest simultaneous assessment of functional polymorphisms within this gene and its expression in larger populations of COVID-19 patients to distinguish the possible correlations. Moreover, VDR has been found to transcriptionally silence TGF- $\beta$ signaling via genomic competition with $\mathrm{Smad} 3$ recruitment on pro-fibrotic and pro-inflammatory genes [28]. Therefore, the observed down-regulation of $V D R$ in COVID-19 cases might result in up-regulation of TGF- $\beta$ signaling and related pathologic events.

Expression levels CYP27B, Linc00511 and Linc00346 were not different between COVID-19 patients and healthy subjects or between their subgroups, implying their independence from COVID-19 infection or disease course.

Significant correlations have been displayed between expression levels of VDR, CYP27B and SNHG6, SNHG16, Linc00511 and Linc00346 lncRNAs both among COVID-19 patients and among normal controls 

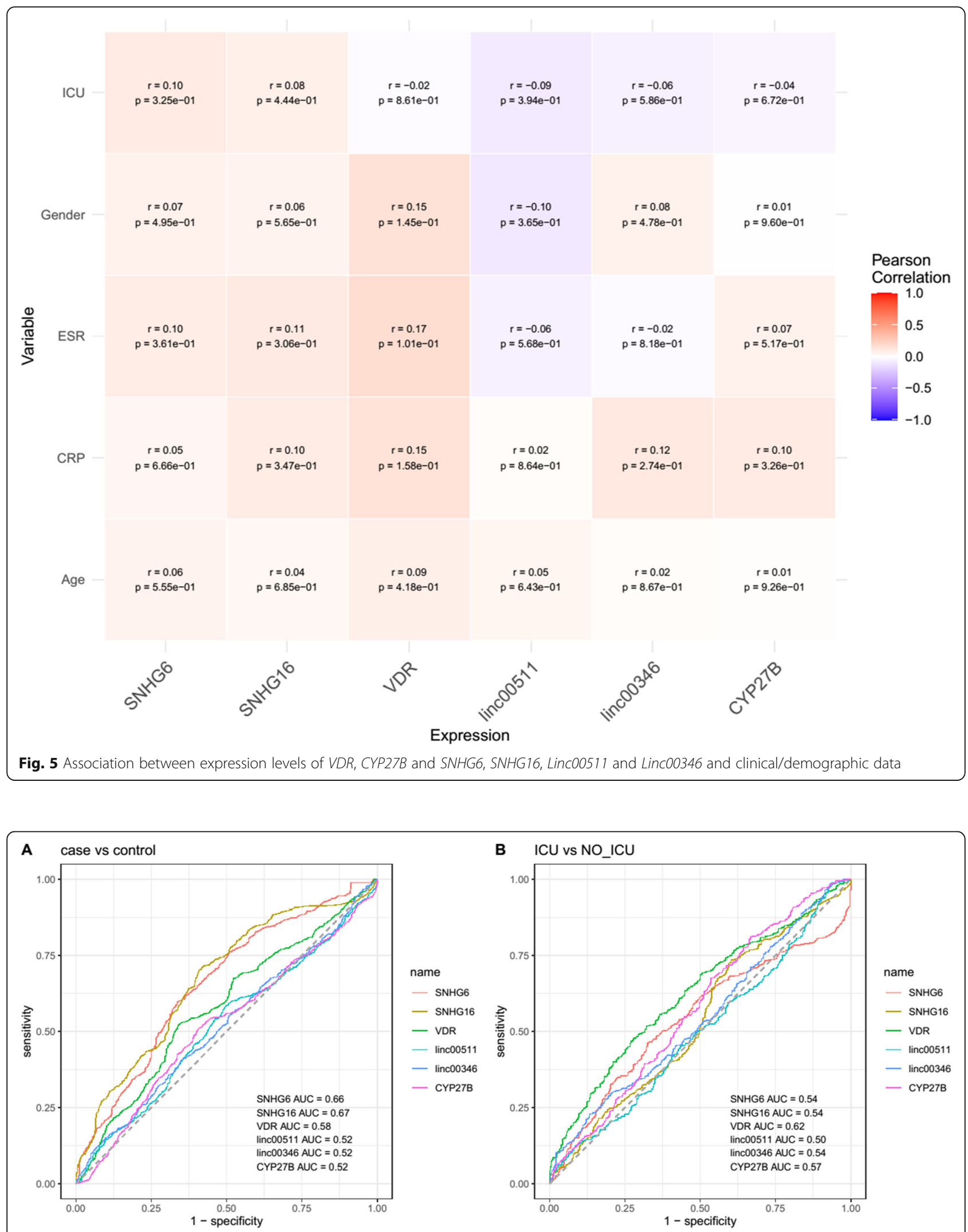

Fig. 6 ROC curves demonstrating the diagnostic power of VDR, CYP27B and SNHG6, SNHG16, Linc00511 and Linc00346 in distinguishing COVID-19 patients from healthy controls (A) and in distinguishing ICU-hospitalized patients from the other group of patients (B) 
Table 3 Detailed parameters of ROC curve assessment for appraisal of the diagnostic power of genes in distinguishing COVID-19 patients from healthy controls and in distinguishing ICU-hospitalized patients from the non-ICU patients (Se: sensitivity, Sp: specifciicty)

\begin{tabular}{|c|c|c|c|c|c|c|c|c|c|c|c|c|c|c|c|c|c|c|c|c|c|}
\hline \multirow[b]{2}{*}{ Number of Samples } & \multicolumn{3}{|c|}{ SNHG6 } & \multicolumn{3}{|c|}{ SNHG16 } & \multicolumn{3}{|l|}{$V D R$} & \multicolumn{3}{|c|}{ Linc00511 } & \multicolumn{3}{|c|}{ Linc00346 } & \multicolumn{3}{|c|}{ CYP27B } & \multicolumn{3}{|l|}{ All } \\
\hline & $\overline{A U C}$ & Se & Sp & AUC & Se & Sp & AUC & Se & Sp & AUC & $\mathrm{Se}$ & Sp & AUC & Se & Sp & $\overline{A U C}$ & Se & Sp & $\overline{A U C}$ & Se & Sp \\
\hline \multicolumn{22}{|c|}{ Total patients/ controls } \\
\hline $91 / 91$ & 0.66 & 0.60 & 0.66 & 0.67 & 0.70 & 0.59 & 0.58 & 0.52 & 0.66 & 0.52 & 0.58 & 0.50 & 0.52 & 0.41 & 0.65 & 0.52 & 0.51 & 0.59 & 0.76 & 0.62 & 0.8 \\
\hline \multicolumn{22}{|l|}{ ICU/Non_ICU } \\
\hline $37 / 54$ & 0.54 & 0.46 & 0.67 & 0.54 & 0.74 & 0.40 & 0.62 & 0.48 & 0.72 & 0.50 & 0.97 & 0.08 & 0.54 & 0.23 & 0.87 & 0.57 & 0.81 & 0.33 & 0.53 & 0.25 & \\
\hline
\end{tabular}

with the most significant ones being SNHG6 and SNHG16. These two lncRNAs have also been shown to correlate with each other in other disease contexts [13], implying their functional interactions in different situations. Expression of these genes were not correlated with paraclinical data indicating the independence of these transcripts from these parameters particularly inflammation markers.

Consistent with the similar levels of expressions of genes between ICU-hospitalized patients and other patients, these genes could not distinguish these two subgroups of patients. However, combination of transcript levels of VDR, CYP27B and SNHG6, SNHG16, Linc00511 and Linc00346 could differentiate patients from controls with moderate power.

Taken together, the current data potentiate SNHG6, SNHG16 and VDR as possible contributors in the COVID-19 infection but not in the severity of ARDS. Future studies should attempt to uncover the fundamental mechanism of this possible contribution and unravel the molecular mediators in this pathway. However, we do not have the data of $25(\mathrm{OH}) \mathrm{D}$ levels of patients and controls. We state this point as a limitation of our study.

\section{Abbreviations}

COVID-19: Coronavirus disease 2019; ARDS: Acute Respiratory Distress syndrome; VDR: Vitamin D receptor; IncRNAs: long non-coding RNAs; CRP: Creactive protein; SARS-CoV: SARS-associated coronavirus

\section{Acknowledgements}

Not applicable.

\section{Authors' contributions}

SGF and MT wrote the manuscript and contributed in study design. LMR, $\mathrm{BMH}$ and FN collected the data and confirmed the patient's diagnosis. AS analyzed the data. All authors approved the manuscript.

\section{Funding}

Not applicable.

\section{Availability of data and materials}

The analysed data sets generated during the study are available from the corresponding author on reasonable request.

\section{Declarations}

Ethics approval and consent to participant

All procedures performed in studies involving human participants were in accordance with the ethical standards of the institutional and/or national research committee and with the 1964 Helsinki declaration and its later amendments or comparable ethical standards. Informed consent forms were obtained from all study participants. Informed consent forms were obtained from all study participants. The study protocol was approved by the ethical committee of Shahid Beheshti University of Medical Sciences

(IR.SBMU.RETECH.REC.1399.592). All methods were performed in accordance with the relevant guidelines and regulations.

\section{Consent of publication}

Not applicable.

\section{Competing interests}

The authors declare they have no conflict of interest.

\section{Author details}

${ }^{1}$ Skull Base Research Center, Loghman Hakim Hospital, Shahid Beheshti University of Medical Sciences, Tehran, Iran. ${ }^{2}$ Department of Molecular and Cell Biology, Faculty of Basic Sciences, University of Mazandaran, Babolsar, Iran. ${ }^{3}$ Department of Pharmacognosy, College of Pharmacy, Hawler Medical University, Erbil, Iraq. ${ }^{4}$ Department of Medical Genetics, Shahid Beheshti University of Medical Sciences, Tehran, Iran.

Received: 10 February 2021 Accepted: 27 May 2021

Published online: 19 June 2021

\section{References}

1. Ghafouri-Fard S, Noroozi R, Vafaee R, Branicki W, Po piech E, Pyrc K, et al. Effects of host genetic variations on response to, susceptibility and severity of respiratory infections. Biomed Pharmacother. 2020;128:110296.

2. Channappanavar R, Perlman S. Pathogenic human coronavirus infections: causes and consequences of cytokine storm and immunopathology. Semin Immunopathol. 2017;39(5):529-39. https://doi.org/10.1007/s00281-017-0629-x.

3. Kim J, Choi SM, Lee J, Park YS, Lee CH, Yim JJ, et al. Effect of reninangiotensin system blockage in patients with acute respiratory distress syndrome: a retrospective case control study. Korean J Crit Care Med. 2017; 32(2):154-63. https://doi.org/10.4266/kjccm.2016.00976.

4. Xu Z, Shi L, Wang Y, Zhang J, Huang L, Zhang C, et al. Pathological findings of COVID-19 associated with acute respiratory distress syndrome. Lancet Respir Med. 2020;8(4):420-2. https://doi.org/10.1016/S2213-2600(20)30076-X.

5. Gouda MM, Shaikh SB, Bhandary YP. Inflammatory and fibrinolytic system in acute respiratory distress syndrome. Lung. 2018;196(5):609-16. https://doi. org/10.1007/s00408-018-0150-6.

6. Quesada-Gomez JM, Entrenas-Castillo M, Bouillon R. Vitamin D receptor stimulation to reduce acute respiratory distress syndrome (ARDS) in patients with coronavirus SARS-CoV-2 infections: Revised Ms SBMB 2020_166. J Steroid Biochem Mol Biol. 2020;202:105719.

7. Bouillon R, Marcocci C, Carmeliet G, Bikle D, White JH, Dawson-Hughes B, et al. Skeletal and Extraskeletal actions of vitamin D: current evidence and outstanding questions. Endocr Rev. 2019;40(4):1109-51. https://doi.org/1 0.1210/er.2018-00126.

8. Martens PJ, Gysemans C, Verstuyf A, Mathieu C. Vitamin D's effect on immune function. Nutrients. 2020;12(5):1248

9. Bikle DD, Patzek S, Wang Y. Physiologic and pathophysiologic roles of extra renal CYP27b1: case report and review. Bone Rep. 2018;8:255-67. https://doi. org/10.1016/j.bonr.2018.02.004. 
10. Bilezikian JP, Bikle D, Hewison M, Lazaretti-Castro M, Formenti AM, Gupta A, et al. Mechanisms in endocrinology: vitamin D and COVID-19. Eur J Endocrinol. 2020;183(5):R133-R47.

11. Noroozi R, Branicki W, Pyrc K, Łabaj PP, Pospiech E, Taheri M, et al. Altered cytokine levels and immune responses in patients with SARS-CoV-2 infection and related conditions. Cytokine. 2020;133:155143. https://doi. org/10.1016/j.cyto.2020.155143.

12. Jiang YJ, Bikle DD. LncRNA: a new player in 1a, 25(OH)(2) vitamin $\mathrm{D}(3) \mathrm{NDR}$ protection against skin cancer formation. Exp Dermatol. 2014;23(3):147-50. https://doi.org/10.1111/exd.12341.

13. Mazdeh M, Zamani M, Eftekharian MM, Komaki A, Arsang-Jang S, Taheri M et al. Expression analysis of vitamin $D$ receptor-associated IncRNAs in epileptic patients. Metab Brain Dis. 2019;34(5):1457-65. https://doi.org/10.1 007/s11011-019-00446-9.

14. Gheliji T, Oskooei VK, Hafez AA, Taheri M, Ghafouri-Fard S. Evaluation of expression of vitamin D receptor related IncRNAs in lung cancer. Noncoding RNA Res. 2020;5(3):83-7.

15. Kholghi Oskooei V, Geranpayeh L, Omrani MD, Ghafouri-Fard S. Assessment of functional variants and expression of long noncoding RNAs in vitamin D receptor signaling in breast cancer. Cancer Manag Res. 2018;10:3451-62. https://doi.org/10.2147/CMAR.S174244.

16. Son K-B, Lee T-J, Hwang S-S. Disease severity classification and COVID-19 outcomes, Republic of Korea. Bull World Health Organ. 2021;99(1):62-6. https://doi.org/10.2471/BLT.20.257758.

17. Evans RM, Lippman SM. Shining light on the COVID-19 pandemic: a vitamin $D$ receptor checkpoint in defense of unregulated wound healing. Cell Metab. 2020;32(5):704-9. https://doi.org/10.1016/j.cmet.2020.09.007.

18. Yadav D, Birdi A, Tomo S, Charan J, Bhardwaj P, Sharma P. Association of vitamin D status with COVID-19 infection and mortality in the Asia Pacific region: a cross-sectional study. Indian J Clin Biochem. 2021:1-6.

19. Zhu M, Wang X, Gu Y, Wang F, Li L, Qiu X. MEG3 overexpression inhibits the tumorigenesis of breast cancer by downregulating miR-21 through the PI3K/Akt pathway. Arch Biochem Biophys. 2019;661:22-30. https://doi.org/1 0.1016/j.abb.2018.10.021

20. Zhao X, Nicholls JM, Chen Y-G. Severe acute respiratory syndromeassociated coronavirus nucleocapsid protein interacts with Smad3 and modulates transforming growth factor- $\beta$ signaling. J Biol Chem. 2008;283(6): 3272-80. https://doi.org/10.1074/jbc.M708033200.

21. Xiong Y, Liu Y, Cao L, Wang D, Guo M, Jiang A, et al. Transcriptomic characteristics of bronchoalveolar lavage fluid and peripheral blood mononuclear cells in COVID-19 patients. Emerg Microbes Infect. 2020;9(1): 761-70. https://doi.org/10.1080/22221751.2020.1747363.

22. Ferreira-Gomes M, Kruglov A, Durek P, Heinrich F, Tizian C, Heinz GA, et al. SARS-CoV-2 in severe COVID-19 induces a TGF- $\beta$-dominated chronic immune response that does not target itself. Nat Commun. 2021;12(1):1-14.

23. Matsuyama T, Kubli SP, Yoshinaga SK, Pfeffer K, Mak TW. An aberrant STAT pathway is central to COVID-19. Cell Death Differ. 2020:1-17.

24. Ni C, Fang Q-Q, Chen W-Z, Jiang J-X, Jiang Z, Ye J, et al. Breast cancerderived exosomes transmit IncRNA SNHG16 to induce CD73+ $\gamma \delta 1$ Treg cells. Signal Transduct Target Ther. 2020;5(1):1-14.

25. Paul S. Shilpi, Lal G. role of gamma-delta ( $\gamma \delta)$ T cells in autoimmunity. J Leukoc Biol. 2015;97(2):259-71. https://doi.org/10.1189/jlb.3RU0914-443R.

26. Mitchell F. Vitamin-D and COVID-19: do deficient risk a poorer outcome? Lancet Diabetes Endocrinol. 2020;8(7):570.

27. Mohan M, Cherian JJ, Sharma A. Exploring links between vitamin D deficiency and COVID-19. PLoS Pathog. 2020;16(9):e1008874-e.

28. Ding N, Ruth TY, Subramaniam N, Sherman MH, Wilson C, Rao R, et al. A vitamin $D$ receptor/SMAD genomic circuit gates hepatic fibrotic response. Cell. 2013;153(3):601-13. https://doi.org/10.1016/j.cell.2013.03.028.

\section{Publisher's Note}

Springer Nature remains neutral with regard to jurisdictional claims in published maps and institutional affiliations.

Ready to submit your research? Choose BMC and benefit from:

- fast, convenient online submission

- thorough peer review by experienced researchers in your field

- rapid publication on acceptance

- support for research data, including large and complex data types

- gold Open Access which fosters wider collaboration and increased citations

- maximum visibility for your research: over $100 \mathrm{M}$ website views per year

At BMC, research is always in progress.

Learn more biomedcentral.com/submissions 